Research Article

\title{
Numerical Simulation of Tandem Shaped Charge Penetrating Armored Target under Explosive Loading
}

\author{
Jianping Yin $\left(\mathbb{D}\right.$, Conghui Duan $\left(\mathbb{D}\right.$, Yangyang Han $\left(\mathbb{D}\right.$, Zhijun Wang $\mathbb{D}^{\circ}$, and Jie Chen \\ School of Mechatronic Engineering, North University of China, Taiyuan 030051, China \\ Correspondence should be addressed to Jianping Yin; yjp123@nuc.edu.cn
}

Received 29 September 2020; Revised 15 April 2021; Accepted 26 April 2021; Published 4 May 2021

Academic Editor: SH Chen

Copyright (C) 2021 Jianping Yin et al. This is an open access article distributed under the Creative Commons Attribution License, which permits unrestricted use, distribution, and reproduction in any medium, provided the original work is properly cited.

\begin{abstract}
Tandem shaped charge is one of the hotspots in the research of antiarmor ammunition at present, but because of the shortcoming that the front-stage jet penetrates and detonates ERA (Explosive Reactive Armor), then it will affect the rear-stage jet to penetrate the main armor. Our research team proposes that the front charge of the tandem shaped charge can be designed as a low-density material charge liner so that the front-stage low-density jet can penetrate a small hole in the reactive armor without detonating. The rear-stage main charge forms a main jet through the small hole to penetrate the main armor. In this article, the damage of tandem shaped charge to armored target is studied when copper and new modified PTFE (polytetrafluoroethylene) materials are used as front-stage charge liner, and the numerical simulation results are verified by experiments. The numerical results show that the $\mathrm{Cu}$ (copper) jet formed by tandem shaped charge of double-copper material has strong impact performance. The interlayer explosive in reactive armor is detonated in the process of penetrating reaction armor, which weakens the penetration ability of the main rear-jet. However, the interlayer explosive in the reactive armor is not detonated during the penetration of the doublematerial tandem shaped charge. The front-stage modified PTFE jet and the rear-stage main jet are not affected by the explosion loading before penetrating the main armor. The experimental results show that the double-material tandem shaped charge overcomes the shortcoming of the influence of the front-stage explosion, and the penetration depth of the main armor reaches $703 \mathrm{~mm}$, which is $14.3 \%$ higher than the penetration ability of the double-copper tandem shaped charge, which is basically consistent with the numerical simulation results. It provides a reference for improving the damage ability of tandem shaped charge to armored target.
\end{abstract}

\section{Introduction}

With the emergence of new concepts, new materials, new structures, and new principles of armor, especially the application of ERA (Explosive reactive armor), the protection capabilities of ground armored vehicles have been improved day by day. As the main protection means for armored targets such as ground armored vehicles, wearing explosive reactive armor can interfere with the penetration of the metal jets formed by the shaped charge to main armor and play an effective role in protecting the main armor. Thus, it presents a serious challenge to the traditional tandem shaped charge warhead $[1,2]$. In this context, how to improve the damage performance of armored target caused by tandem shaped charge warheads has become one of the focuses and hotspots in the field of armament science and technology at home and abroad [3-12].
Explosive reactive armor (ERA) is an important protective means for main battle tanks and armored vehicles to defend shaped charge warheads, as proposed by Held in 1969. When a shaped charge jet impacts the ERA, the Sandwich charge will be detonated by the shaped charge jet; thus, separating the front and the back plates along the normal direction at a certain speed as driven by the explosive load, cutting the jet and significantly weakening the damage performance of the shaped charge jet. In addition, detonation products with high temperature, high pressure, and high-speed mixed with metal fragments produce a side resistance to the shaped charge jet, making the shaped charge jet twist, break, and fly away. A combination of the two reduces the penetration depth of the shaped charge jet on the main armor. At present, a tandem shaped charge warhead is used to destroy such targets; that is, the front 
shaped charge warhead destroys the ERA, and the main charge experiences delayed detonation, and then, the main jet penetrates the main armor. The conventionally shaped charge liners primarily comprise metallic materials, including copper, iron, and aluminium, among others. In recent years, extensive research has been conducted on the problems related to the shaped charge jet impact on ERA. Through many experiments, Held [13-19] studied the interaction mechanism between armor and jet, analyzed the influence laws of the thickness of the Sandwich charge, detonation velocity, metal plate thickness, and jet impact angle, and proposed the famous $v^{2} d$ initiation criterion, which greatly contributed to the development of ERA.

The main means of antireactive armor is to use tandem warhead in traditional shaped charge technology, the ERA is detonated by the front-stage warhead, and the rear-stage warhead penetrates the main armor with advance. But this kind of tandem warhead has some shortcomings. Because the detonation products and detonation wave produced by the front-stage have very high pressure and velocity, it will produce strong compression and impact on the main jet formed by the rear main warhead. The high velocity part of the main jet is deflected and dispersed, and the main jet formed by the rear main warhead is disturbed and destroyed by ERA, which cannot effectively play its antiarmor role $[20,21]$. In view of this situation, researchers at home and abroad have proposed that the front-stage warhead of tandem warhead should be designed into a low-density material warhead [22-25]. In this way, under the action of explosive loading, the front-stage low-density jet penetrates a small hole in the reactive armor but does not detonate, then the rear-stage main warhead forms a main jet through the hole to penetrate the main armor, thus realizing the penetration to reactive armor without detonation; meanwhile, the effect of the front-stage jet penetrating ERA on the penetration performance of the rear-stage main jet is avoided, and the penetration power of the rear-stage shaped charge to the main armor is improved effectively. At the same time, domestic and foreign experts and scholars have studied the materials that form low-density jets [22, 26-29], by improving the dynamic mechanical properties and unit specific kinetic energy of low-density materials under explosive loading, it is intended to achieve the ability to penetrate but not detonate reactive armor and effectively improve the penetration ability of low-density jets.

The purpose of this paper is to study the damage performance of tandem shaped charge penetrating armored target wearing "reactive armor," which is based on the establishment of the target structure model and finite element model of the tandem shaped charge penetrating the armor target wearing "reactive armor," with the penetration depth of the armored target as the weighing technical index; the finite element software is used to simulate the penetration to armored target by tandem shaped charge under explosive loading. The influence of copper liner and modified PTFE liner on the penetration performance of tandem shaped charge is analyzed, which provides a reference for improving the ability of tandem shaped charge to damage armored target.

\section{Numerical Simulation}

2.1. Finite Element Model. In order to study the damage performance of tandem charge to armored target wearing ERA, the tandem charge was designed to penetrate $45 \#$ steel target after penetrated reactive armor, and the damaging effect of tandem shaped charge on tank target wearing ERA was simulated by Autodyn14.0 software. The finite element model of the tandem shaped charge penetrating the armored target is shown in Figure 1. The front part was a tandem shaped charge, the middle was a reactive armor, and the back was a simulated armor. For the front shaped charge, the charge diameter was $40 \mathrm{~mm}$, the charge height was $40 \mathrm{~mm}$, the liner cone angle was $55^{\circ}$, and the wall thickness of the liner was $3.5 \mathrm{~mm}$. In the rear shaped charge, the charge diameter was $90 \mathrm{~mm}$, the charge height was $175 \mathrm{~mm}$, liner cone angle was $45^{\circ}$, and wall thickness was $2.5 \mathrm{~mm}$. The distance between the front and the rear warhead was $160 \mathrm{~mm}$, the blasting height of the front warhead was 3 times the charge diameter, and the distance from the ERA to the target was $80 \mathrm{~mm}$.

The finite element software was used to simulate the penetration of tandem shaped charge to armored target. Because the formation and penetration of shaped charge jet is a problem of large deformation of the material, the multimaterial Euler algorithm is adopted. In order to better present the jet shape, gradient grid technology is used to encrypt the grid in the axisymmetric direction. The size of the air domain is $1200 \mathrm{~mm} \times 120 \mathrm{~mm}$, and the mesh size is $2400 \times 240$. The "flow out" boundary condition is added to the boundary of the air domain to avoid the reflection of stress on the boundary. When it was calculated to $102 \mu \mathrm{s}$, the front-stage low-density jet penetrated but not detonated the reactive armor and opened the channel for the rear-stage main jet penetrating the 45\# steel target on the reactive armor plate and the back plate. At this point, the computational time step was too small to be simulated for a long time, so the paper selected the calculation file, which was kept at $100 \mu \mathrm{s}$ and used AUTODYN mapping technology to map the main jet to the Euler domain. At $137 \mu \mathrm{s}$, in order to improve the calculation speed, the mapping technique was used again, and the main jet mapped to Lagrange was numerically simulated.

For the mapping technique, simply speaking, because of the obvious size effect of the grid in the process of the explosion, only a small grid can simulate the shock wave in the early stage of explosion. If the grid is large, the peak pressure of the shock wave will become very low. However, due to the limited performance of the computer, we usually establish a 2D model first and then import the $2 \mathrm{D}$ results into the $3 \mathrm{D}$ model to facilitate other calculations. In this paper, the map file is generated by $2 \mathrm{D}$ explosion calculation and then extracted into the $3 \mathrm{D}$ model to calculate the penetration process. Therefore, at $100 \mu \mathrm{s}$, the shaped charge jet needs to be mapped to the Euler domain to penetrate the explosive reactive armor. At $137 \mu \mathrm{s}$, the jet needs to be mapped to the Lagrangian domain to improve the calculation speed of the penetration process.

2.2. Material Models and Parameters. In numerical simulation, $\mathrm{Cu}$ and modified PTFE were used as liner materials 


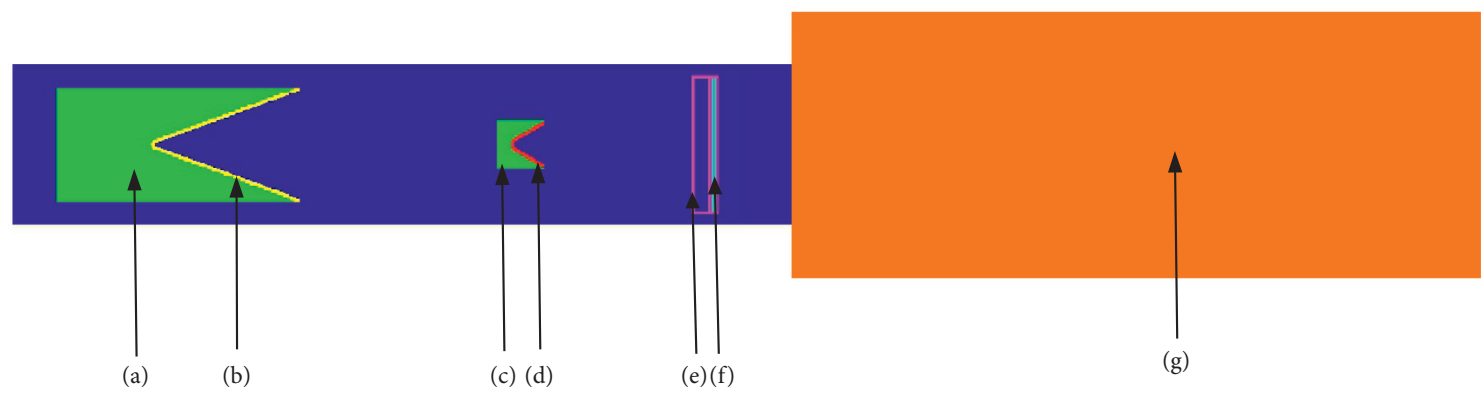

Figure 1: Finite element model of jet formed by tandem shaped charge penetrating the armored target. (a) Rear main charge. (b) Rear liner. (c) Front main charge. (d) Front liner. (e) Shield panel. (f) Sandwich charge. (g) Main armor.

for tandem shaped charge, the target material was $45 \#$ steel, and the main charge was comp B explosive.

The main charge of the tandem shaped charge in the numerical simulation calculation was comp B explosive. Basic parameters were shown in Table 1. The Jones-Wilkins-Lee equation of state (EOS_JWL) was chosen to describe the comp B (explosive B) properties. The JWL state equation accurately described the pressure, volume, and energy characteristics of the detonation gas products during the explosion-driven process. The expression is as follows:

$$
p=A\left(1-\frac{\omega}{R_{1} V}\right) e^{-R_{1} V}+B\left(1-\frac{\omega}{R_{2} V}\right) e^{-R_{2} V}+\frac{\omega E_{0}}{V}
$$

where, $A, B, R_{1}, R_{2}$ and $\omega$ are input parameters; $E_{0}$ is the initial specific internal energy; $V$ is the initial relative volume of the detonation products.

In the tandem shaped charge, the front-stage liner material was modified PTFE, the modified PTFE material was obtained by adding a copper powder having a mass fraction of $38.5 \%$ and a density of $8.93 \mathrm{~g} / \mathrm{cm}^{3}$ to a PTFE matrix, and the rear-stage liner material was copper. Under the action of detonation products, the liner material can be considered as an ideal fluid elastic-plastic model, and the strength of the liner material cannot be considered. Therefore, von-Mises yield criterion, instantaneous failure principle, and shock equation of state can be used to describe the dynamic response behavior of the liner material under the action of detonation wave and to calculate the large deformation of the material under the condition of high strain $\left(>10^{5} \mathrm{~s}^{-1}\right)$. The liner material parameters of copper and modified PTFE were shown in Table 2.

The target plate material was made of $45 \#$ steel, which showed a certain strain rate effect under different impact, while the Johnson-Cook model has a very good advantage in describing the strain rate effect of metal materials, and its form is relatively simple so it is also widely used. Therefore, the J-C model was used to describe the constitutive relationship of $45 \#$ steel, and some of its material parameters were shown in Table 3.

The equation of state of air was chosen as Ideal Gas. The main parameters are as follows: density is $\rho=1.293 \times 10^{-3} \mathrm{~g} / \mathrm{cm}^{3}$, speed of sound is $C=340 \mathrm{~m} / \mathrm{s}$, initial relative volume is $V_{0}=1.0$.

\section{Numerical Simulation of Jet Formation and Penetration}

In order to better understand the influence of the traditional shaped charge liner material on the penetration performance of front-stage charge of tandem shaped charge, the numerical simulation of penetrating armored target was carried out by two kinds of tandem shaped charge, front-stage copper liner and modified PTFE liner, respectively. The tandem shaped charge was called double-copper material tandem shaped charge for short, for which, copper was used for both the front-stage charge and the rear-stage charge liner. And another tandem shaped charge was called doublematerial tandem shaped charge for short, for which, modified PTFE material was used for front-stage charge liner and copper for rear-stage charge liner.

\subsection{Penetration of Armored Target by Double-Copper Tandem} Shaped Charge. When both the front-stage charge and the rear-stage charge liner of the tandem shaped charge were all made of copper, the finite element software was used to study the jet penetrating reactive armor and main armor under explosive loading. Through numerical simulation, the penetration process of the double-copper material tandem shaped charge penetrating the armored target at a typical time was shown in Figure 2.

In the penetration process of the double-copper tandem shaped charge to the armored target, after the detonation of the tandem shaped charge, at about $35 \mu \mathrm{s}$, the copper jet formed in the front-stage charge region began to penetrate into the reactive armor, about $45 \mu \mathrm{s}$, the reactive armor was detonated by the front-stage copper jet. After the reactive armor was detonated, the flying plate effect was generated. The front-stage jet was disturbed by the detonation wave and lost the penetration ability, and the rear-stage main jet would also be subject to certain interference. The main jet that was disturbed starts to penetrate the main armor at about $150 \mu \mathrm{s}$ when the detonation product of the front warhead loses its effect on the secondary main jet, and in order to improve the efficiency of numerical simulation, the main jet was mapped, and the penetration process of the main jet to the main armor was shown in Figure 3.

At $150 \mu \mathrm{s}$, the rear-stage main jet began to penetrate the main armor at a speed of $4970 \mathrm{~m} / \mathrm{s}$. The velocity of the jet head decreased rapidly after it contacted the main armor. 
TABLE 1: Basic parameters of comp B explosive [5].

\begin{tabular}{lccccccccc}
\hline Parameters & $\rho_{\mathrm{o}}\left(\mathrm{g} / \mathrm{cm}^{3}\right)$ & $D(\mathrm{~km} / \mathrm{s})$ & $A(\mathrm{GPa})$ & $B(\mathrm{GPa})$ & $R_{1}$ & $R_{2}$ & $\omega$ & $E_{0}\left(\mathrm{~kJ} / \mathrm{m}^{3}\right)$ & $\mathrm{P}_{\mathrm{C}-\mathrm{J}}(\mathrm{GPa})$ \\
\hline Numerical value & 1.717 & 7.98 & 524.23 & 7.678 & 44.2 & 11.1 & 0.34 & $8.5 \mathrm{e} 6$ & 29.5 \\
\hline
\end{tabular}

TABLE 2: Basic parameters of liner materials [25].

\begin{tabular}{|c|c|c|c|c|c|c|c|}
\hline$\underline{\text { Parameters }}$ & EOS & $\rho /\left(\mathrm{g} / \mathrm{cm}^{3}\right)$ & $\mathrm{G} / \mathrm{GPa}$ & $s_{\mathrm{Y}} / \mathrm{MPa}$ & Gruneisen coefficient & $\mathrm{C}_{1}(\mathrm{~km} / \mathrm{s})$ & $\mathrm{S}_{1}$ \\
\hline \multirow[b]{2}{*}{ Copper } & Shock & 8.93 & 47.7 & 90 & 1.99 & 3.94 & 1.489 \\
\hline & $\begin{array}{l}\text { Strength } \\
\text { von-Mises }\end{array}$ & & $\begin{array}{c}G / M b a r \\
0.46\end{array}$ & & \multicolumn{3}{|c|}{$\begin{array}{c}\sigma s / M p a \\
900\end{array}$} \\
\hline \multirow{4}{*}{ Modified PTFE } & EOS & $\rho /\left(\mathrm{g} / \mathrm{cm}^{3}\right)$ & $\mathrm{G} / \mathrm{GPa}$ & $s_{\mathrm{Y}} / \mathrm{MPa}$ & Gruneisen coefficient & $\mathrm{C}_{1}(\mathrm{~km} / \mathrm{s})$ & $\mathrm{S}_{1}$ \\
\hline & Shock & 3.05 & 1.37 & 46 & 0.90 & 1.34 & 1.930 \\
\hline & Strength & & G/Mbar & & \multirow{2}{*}{\multicolumn{3}{|c|}{$\begin{array}{l}\sigma_{s} / M p a \\
500.000\end{array}$}} \\
\hline & von-Mises & & 0.2330 & & & & \\
\hline
\end{tabular}

TABLE 3: Basic parameters of 45\#steel [6].

\begin{tabular}{cccccccc}
\hline 45\#steel & $\rho /(\mathrm{g} /$ & $G /$ & $K /$ & $A /$ & $B /$ & $C$ & $n$ \\
& $\left.\mathrm{~cm}^{3}\right)$ & $(\mathrm{Gpa})$ & $(\mathrm{Gpa})$ & $(\mathrm{Gpa})$ & $(\mathrm{Gpa})$ & & \\
\hline & 7.85 & 81.8 & 148 & 0.507 & 0.32 & 0.28 & 0.064 \\
& $m$ & $D_{1}$ & $D_{2}$ & $D_{3}$ & $D_{4}$ & $D_{5}$ & \\
& 1.06 & 0.10 & 0.76 & 1.57 & 0.005 & -0.84 & \\
\hline
\end{tabular}

However, due to the continuous impact of the subsequent high-speed jet on the armor, the armor material was extruded and deformed to form a penetration into the main armor.

Through the numerical simulation of the penetration process of the tandem shaped charge with double-copper material to armored target, it can be seen that when the copper material was used in the front-stage charge liner of the tandem shaped charge, the copper jet could not effectively achieve the penetration but not detonation to the reactive armor which is in front of the main armor, but would detonate the reactive armor. And the ERA would have a great effect on the rear-stage main jet, resulting in a penetration depth of $627 \mathrm{~mm}$ for the double-copper tandem shaped charge to main armor, as shown in Figure 4.

\subsection{Penetration of Armored Target by Jet Formed by Double-} Material Tandem Shaped Charge. The numerical simulation of penetrating reactive armor and main armor was carried out by using AUTODYN software when the front-stage charge of the tandem shaped charge was modified PTFE charge liner and the copper charge liner was used for the rear-stage charge. The penetration process of the doublematerial tandem shaped charge against the armored target at a typical time was shown in Figure 5.

In the penetration process of the double-material tandem shaped charge to the armored target, after the detonation of the tandem shaped charge, at about $30 \mu \mathrm{s}$, the modified PTFE jet formed by the front-stage charge began to penetrate the reactive armor, and the penetration of reactive armor was completed at about $40 \mu \mathrm{s}$. It can be seen from Figure 6 that the front-stage modified PTFE jet did not detonate after penetrated the reactive armor and began to penetrate the main armor at $60 \mu \mathrm{s}$. Since the reactive armor was not detonated under the action of the front-stage modified PTFE jet, the reactive armor did not interfere with the rear-stage main jet.

In order to analyze the damage effect of the rear-stage main jet to the main armor, and to improve the efficiency of numerical simulation, after $100 \mu$ s, the explosive, reactive armor, and the front-stage jet were deleted because both the detonation products and the reactive armor of the frontstage charge lost their functions, and the main jet of the rearstage after $130 \mu$ s began to penetrate the main armor. In order to further improve the efficiency of the numerical simulation, the main jet was mapped, and the penetration process of the main armor by the mapped main jet was shown in Figure 6.

At $130 \mu \mathrm{s}$, the main jet of the rear-stage charge began to penetrate the main armor at the speed of $6470 \mathrm{~m} / \mathrm{s}$, and the velocity of the jet head decreased rapidly after contacting with the main armor. However, due to the continuous impact on the armor by the subsequent high-speed jet, the armor material was extruded to form a penetration into the main armor.

Through the numerical simulation of the penetration process of the double-material tandem shaped charge to armored target, it can be seen that the modified PTFE material was used in the front-stage liner of the tandem shaped charge; the modified PTFE jet could effectively penetrate the main armor in front reaction armor without detonating. At the same time, the modified PTFE jet had a certain damage effect on the main armor after penetrating the reactive armor, and the penetration depth of the doublematerial tandem shaped charge to the main armor was $721 \mathrm{~mm}$, as shown in Figure 7.

3.3. Comparison and Analysis. The penetration process of the jets formed by the double-copper tandem shaped charge and the double-material tandem shaped charge penetrating reactive armor was shown in Figures 2 and 6. The results of numerical simulation show that the frontstage liner material in the double-copper tandem shaped charge was a high-density $\mathrm{Cu}$ material; the $\mathrm{Cu}$ jet had strong impact property; it was easy to detonate the interlayer explosive in the reactive armor in the process of 


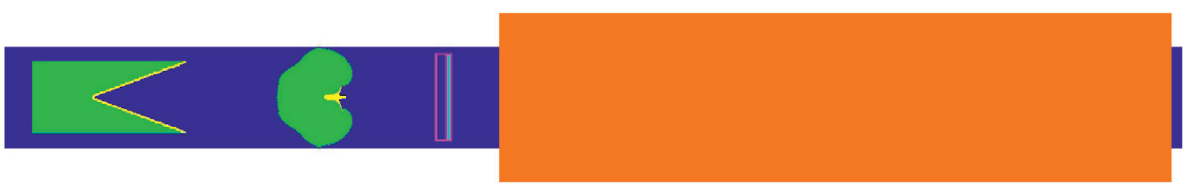

(a)

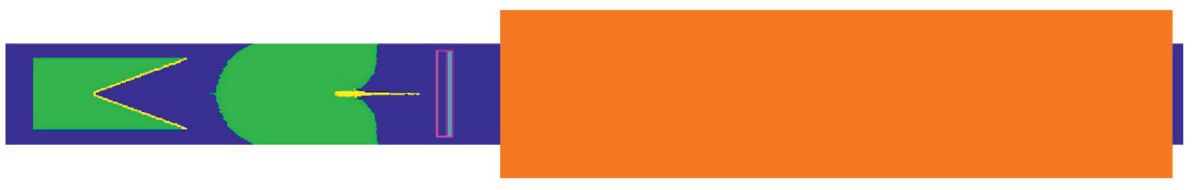

(b)

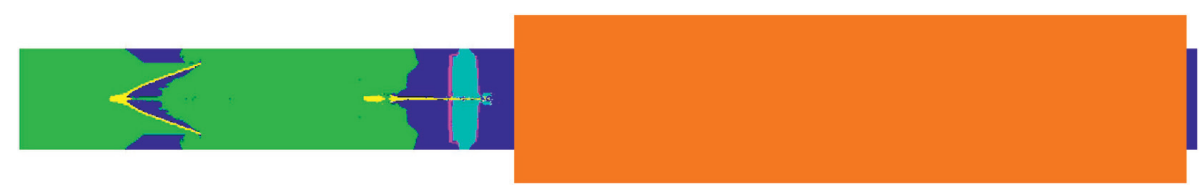

(c)

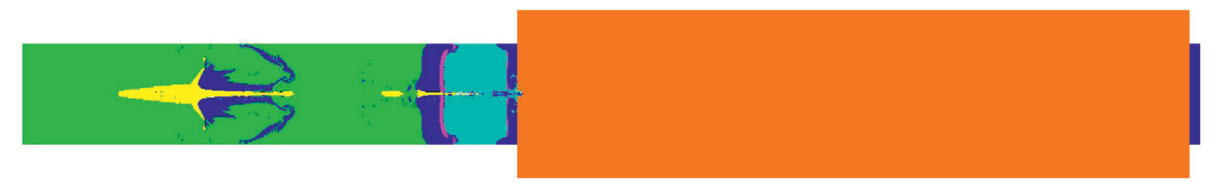

(d)

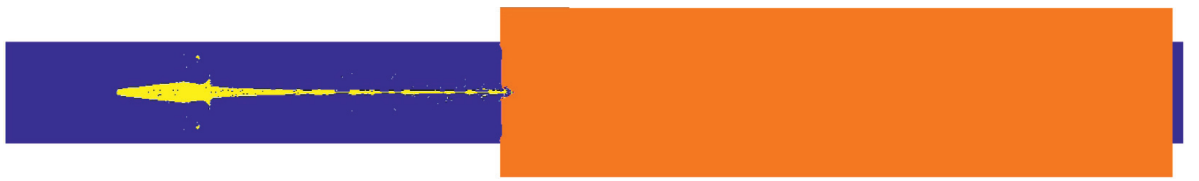

(e)

FigURE 2: The penetration process of double-copper tandem shaped charge to armored target before $150 \mu \mathrm{s}$. (a) $\mathrm{t}=10 \mu \mathrm{s}$. (b) $\mathrm{t}=30 \mu \mathrm{s}$. (c) $\mathrm{t}=60 \mu$ s. (d) $\mathrm{t}=90 \mu$ s. (e) $\mathrm{t}=150 \mu \mathrm{s}$.

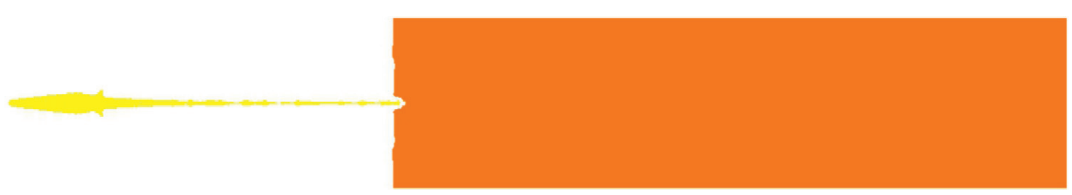

(a)

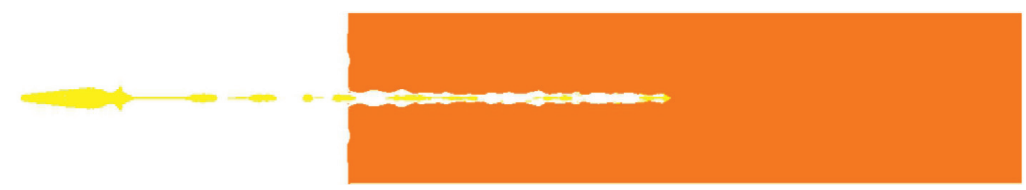

(b)

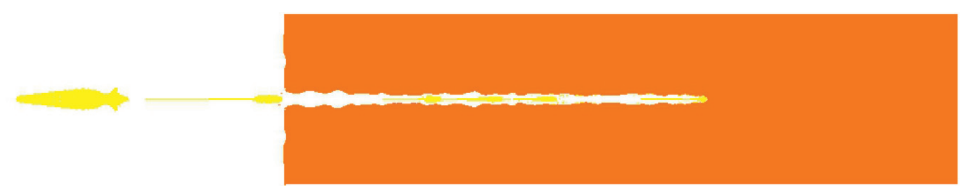

(c)

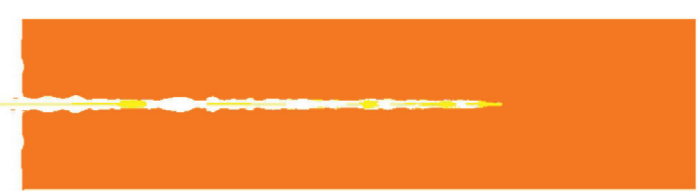

(d)

Figure 3: Continued. 


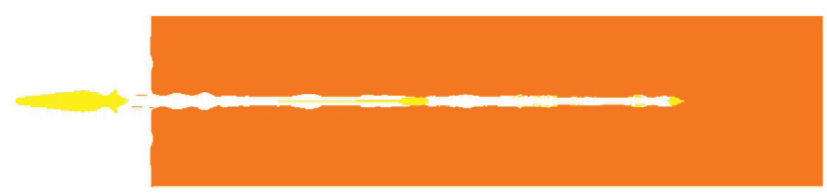

(e)

Figure 3: Penetration process of armored target by double-copper tandem shaped charge after $150 \mu \mathrm{s}$. (a) $\mathrm{t}=150 \mu \mathrm{s}$. (b) $\mathrm{t}=350 \mu \mathrm{s}$. (c) $\mathrm{t}=550 \mu \mathrm{s}$. (d) $\mathrm{t}=750 \mu \mathrm{s}$. (e) $\mathrm{t}=1000 \mu \mathrm{s}$.

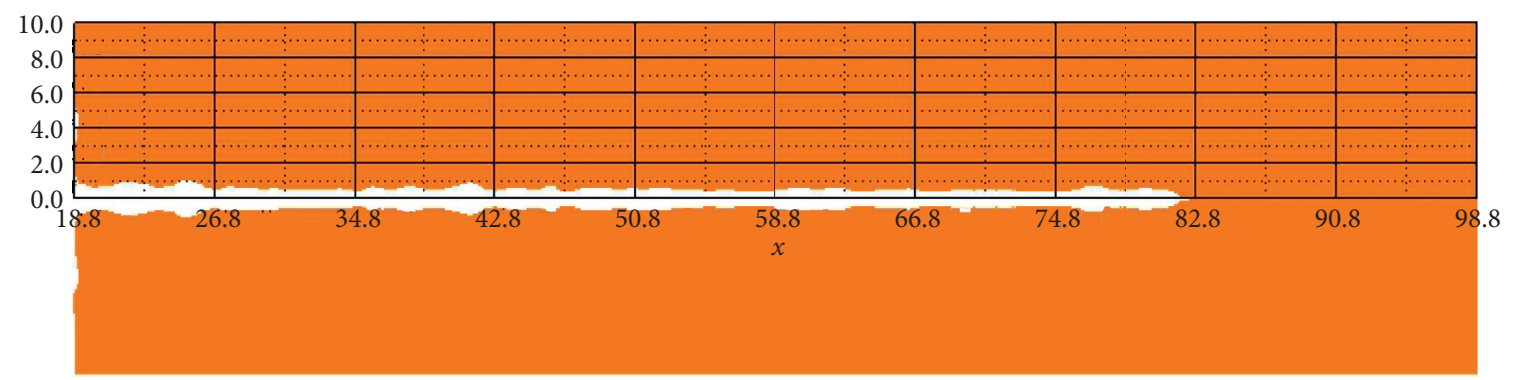

FIGURE 4: The penetration results of main armor by rear-stage main jet of double-copper tandem shaped charge (unit: mm).

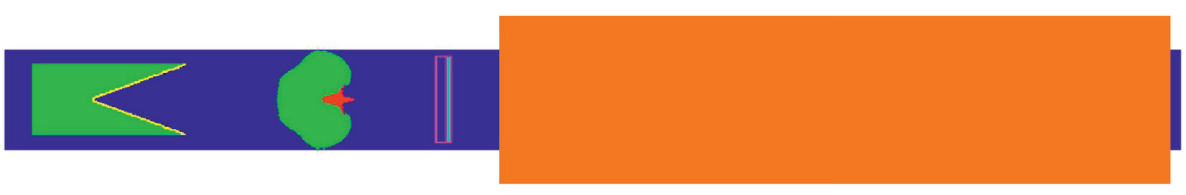

(a)

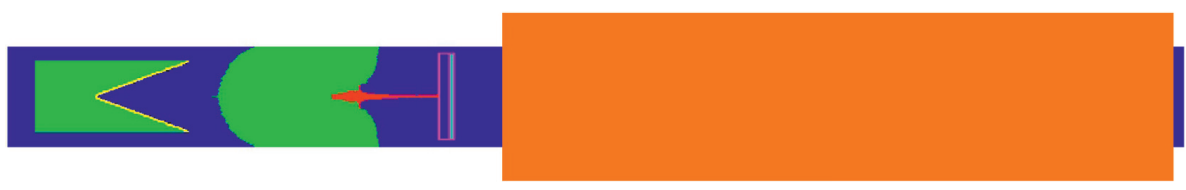

(b)

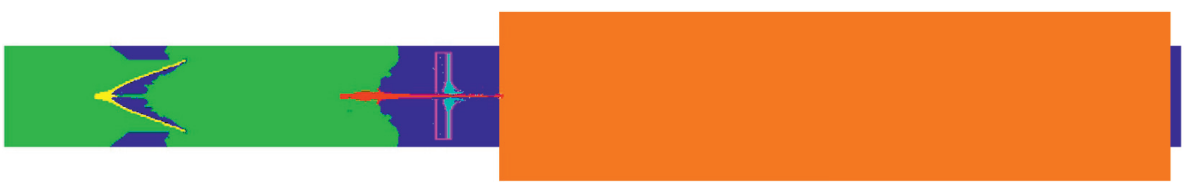

(c)

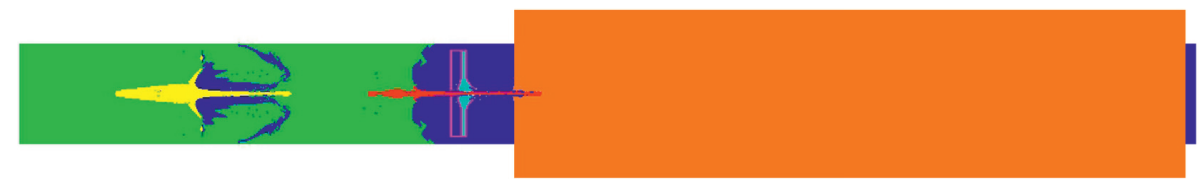

(d)

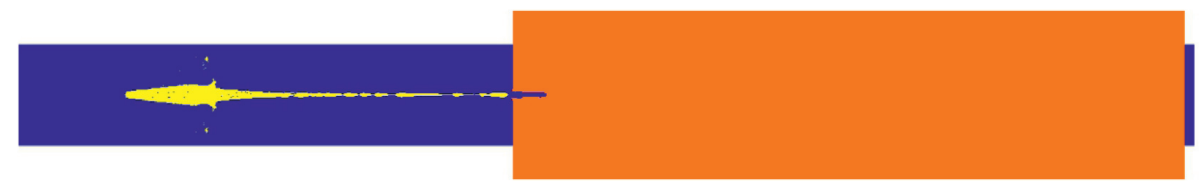

(e)

FIGURE 5: Penetration process of armored target by double-material tandem shaped charge before $130 \mu \mathrm{s}$. (a) $\mathrm{t}=10 \mu \mathrm{s}$. (b) $\mathrm{t}=30 \mu \mathrm{s}$. (c) $\mathrm{t}=60 \mu \mathrm{s}$. (d) $\mathrm{t}=90 \mu \mathrm{s}$. (e) $\mathrm{t}=130 \mu \mathrm{s}$.

penetrating reactive armor. At $40 \mu \mathrm{s}$, the front-stage $\mathrm{Cu}$ jet of the double-copper tandem warhead began to penetrate the interlayer explosive in the reactive armor. At $50 \mu \mathrm{s}$, all the interlayer explosive in the reactive armor had been detonated, and the influence on the front-stage jet had begun. At $100 \mu \mathrm{s}$, the high velocity of the $\mathrm{Cu}$ jet was 


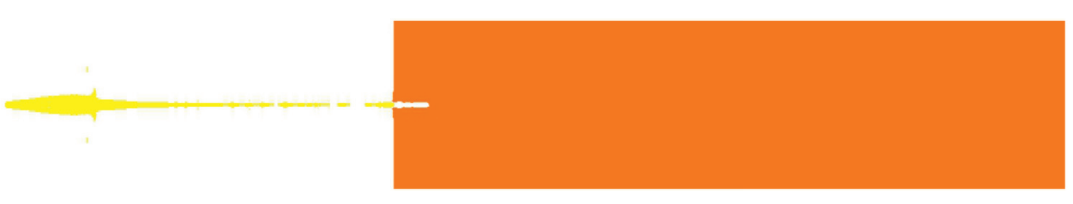

(a)

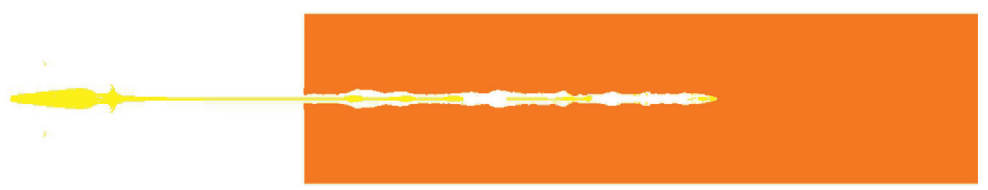

(b)

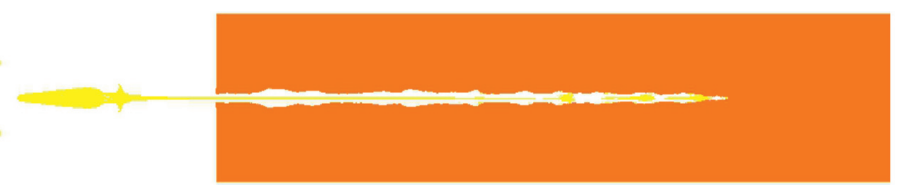

(c)

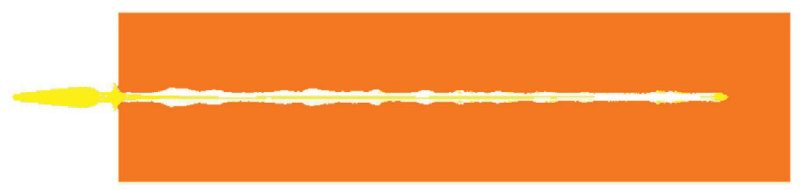

(d)

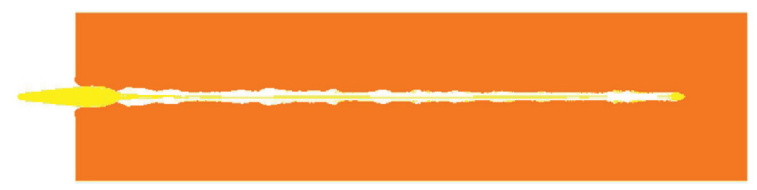

(e)

FiguRE 6: The penetration process of armored target by double-material tandem shaped charge after $130 \mu \mathrm{s}$. (a) $\mathrm{t}=130 \mu \mathrm{s}$. (b) $\mathrm{t}=450 \mu \mathrm{s}$. (c) $\mathrm{t}=750 \mu \mathrm{s}$. (d) $\mathrm{t}=1050 \mu \mathrm{s}$. (e) $\mathrm{t}=1200 \mu \mathrm{s}$.

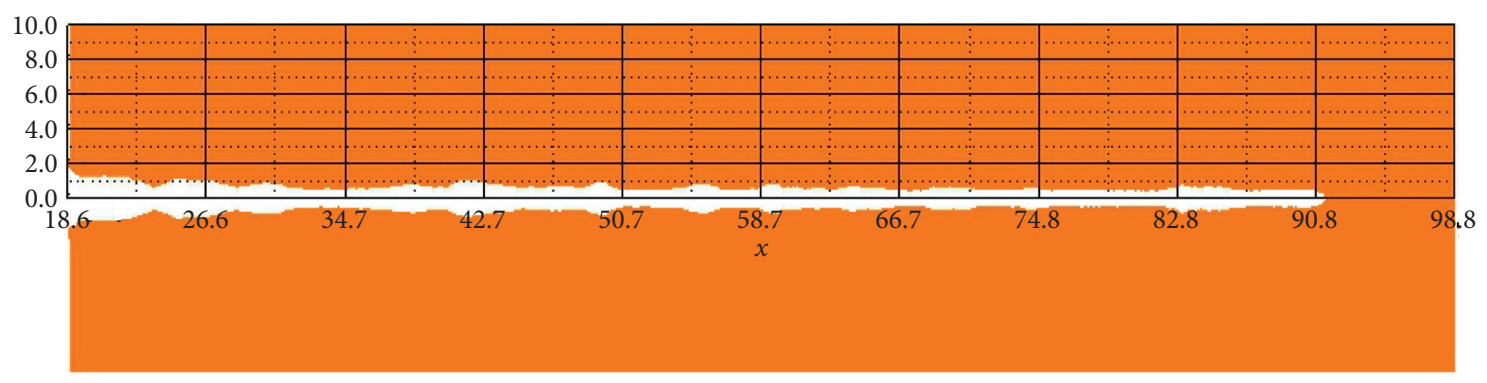

FIgURE 7: Penetration results of armored target by double-material tandem shaped charge (unit: $\mathrm{mm}$ ).

dispersed under the detonation wave of the Sandwich explosive, and the penetration ability was lost, while the part of the lower velocity pestle was less affected by the detonation wave, but also because the velocity of the frontstage copper jet was low, at $110 \mu \mathrm{s}$, part of the pestle body was overtaken by the rear-stage main jet, which was interfered with the rear-stage main jet.

Since the front-stage liner material in the double-material tandem shaped charge was a low-density modified PTFE material, the front-stage modified PTFE jet formed by the double-material tandem shaped charge did not detonate the reactive armor in the process of penetrating armor, so neither the front-stage modified PTFE jet nor the rear-stage main jet was affected by the detonation of interlayer explosive and the fly-plate effect of reactive armor before penetrating the main armor.

By comparing the penetration depth curve of the jets formed by the double-material tandem shaped charge and the double-copper tandem shaped charge to the main armor (as shown in Figure 8), it can be seen that the doublecopper tandem shaped charge front-stage jet was affected by the explosion of the Sandwich explosive after penetrating the reactive armor, the front-stage jet completely lost the penetration ability, and the rear-stage jet was also disturbed; finally, the penetration depth of the doublecopper tandem shaped charge to the main armor was 


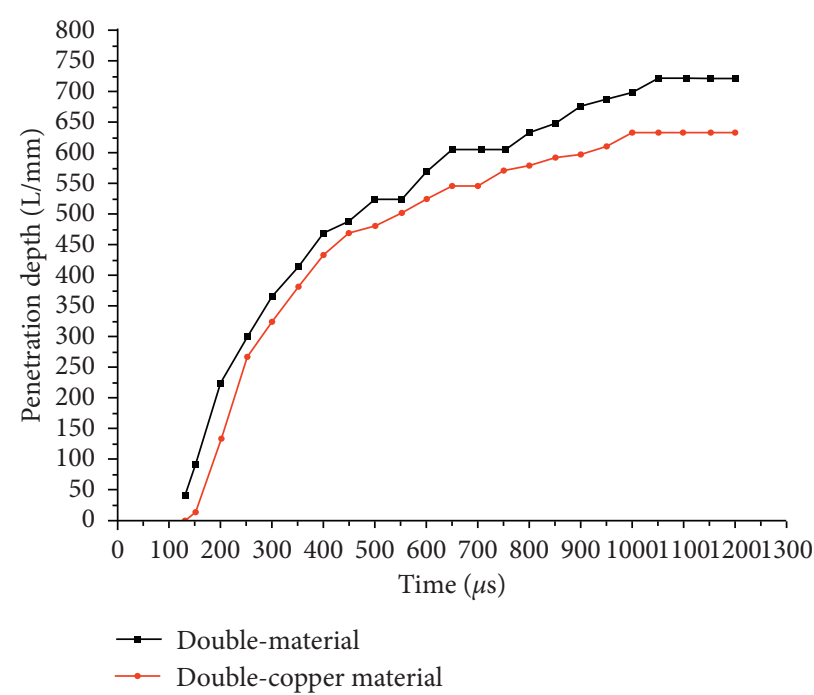

Figure 8: Penetration depth curve of two kinds of tandem shaped charge jets penetrating into main armor.

$627 \mathrm{~mm}$. Since the front-stage jet of the double-material tandem shaped charge was not affected by the explosion of the Sandwich explosive after penetrating the reactive armor, it could continue to penetrate the main armor after penetrating the reactive armor. Finally, the penetration depth of the double-material tandem shaped charge to the main armor was $721 \mathrm{~mm}$, and the penetration ability was increased by $15.0 \%$.

\section{Experimental Verification}

It is a complicated dynamic process for the jet formed by tandem shaped charge penetrating the armored target. The numerical simulation cannot completely describe the real situation in order to obtain a more realistic penetration effect. An experimental study was carried out to verify the penetration of two tandem shaped charges into the main armor. The experimental layout is shown in Figure 9, including the tandem warhead, the blasting height tube, the ERA, and the main armor. The front shaped charge, $D_{2}$ is the charge diameter of $40 \mathrm{~mm}, \mathrm{H}_{2}$ is the charge height of $40 \mathrm{~mm}, \alpha_{2}$ is the cone Angle of the charge type and $2 \alpha_{2}=55^{\circ}$, and $\delta_{2}$ is the wall thickness of the charge type cover $3.5 \mathrm{~mm}$. The tail shaped charge, $D_{1}$, is $90 \mathrm{~mm}$ in diameter, $\mathrm{H}_{1}$ is $175 \mathrm{~mm}$ in height, $\alpha_{1}$ is the cone Angle of the charge column and $2 \alpha_{1}=45^{\circ}$, and $\delta_{1}$ is $2.5 \mathrm{~mm}$ in wall thickness. $H$ is the distance between the front and rear warheads of $160 \mathrm{~mm}, Z_{1}$ is the blasting height of the front warhead, which is 3 times the diameter of the charge of $D_{2}$, and $Z_{2}$ is the distance between ERA and target of $80 \mathrm{~mm}$. In order to ensure that the armor-piercing jet runs in the ERA and the reaction armor, the central axis of the tandem warhead was placed perpendicular to the ERA and the ingot target and centered. After the detonating fuse was detonated, then the tandem warhead was detonated, and the damage element was gradually formed and penetrated the armor. The experimental results obtained are shown in Figures 10 and 11 .

Through the experiments of tandem shaped charge penetrating the target of "reactive armor," it was proved that after the front-stage charge adopted the modified PTFE charge liner, under the action of explosion loading, the penetration of reactive armor could be realized without detonation. It solved the engineering problem that the frontstage jet penetrated and detonated reactive armor, which affected the penetration power of the rear-stage main jet penetrating the main armor. Through the experimental study on the penetration of the main armor by the main jet, the penetration depth of the jet penetrating the main armor was $615 \mathrm{~mm}$. The double-material tandem shaped charge overcame the shortcoming of the influence of the front-stage explosion, and the penetration depth of the main armor reached $703 \mathrm{~mm}$, which was $14.3 \%$ higher than the penetration ability of the double-copper tandem shaped charge, which was basically consistent with the numerical simulation results. A comparative analysis of jets formed by two kinds of tandem shaped charge penetrating targets is shown in Table 4. 


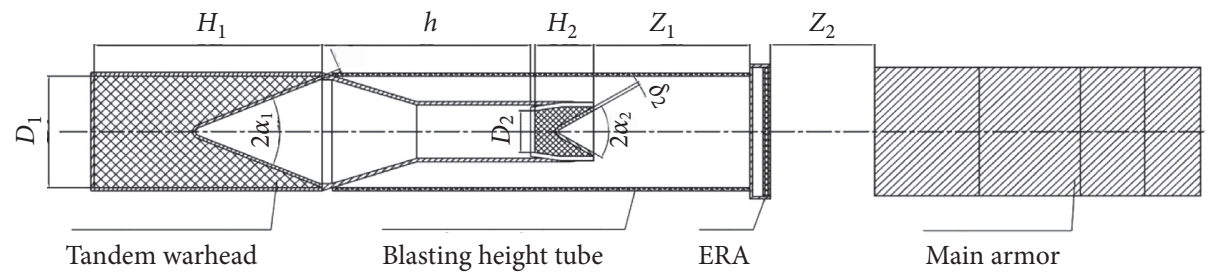

FIGURE 9: Experimental layout.

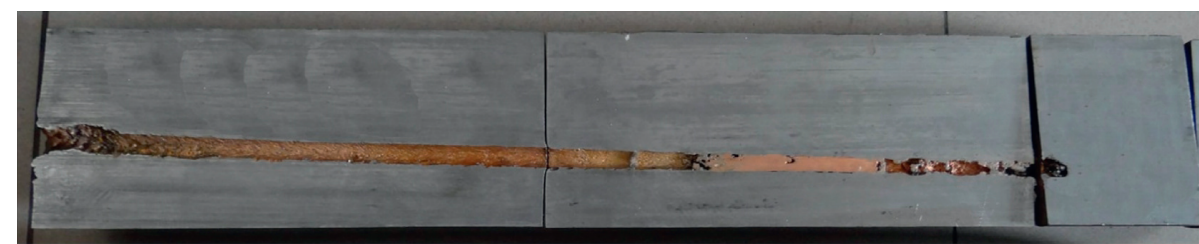

FiguRE 10: Experimental result of jet formed by tandem shaped charge of double-copper material penetrating main armor.

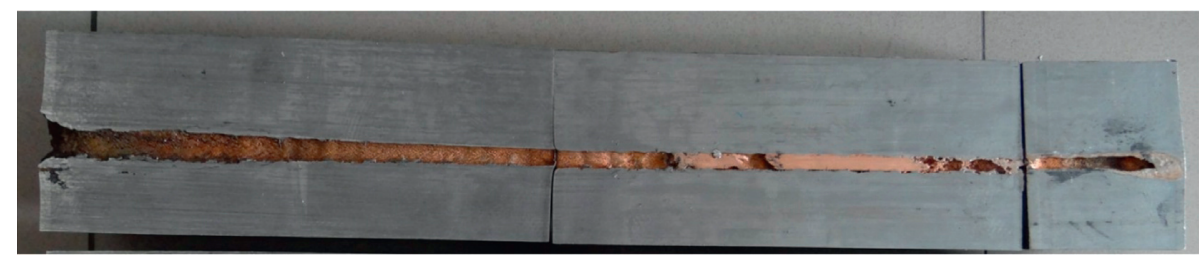

FIGURE 11: Experimental result of jet formed by double-material tandem shaped charge penetrating main armor.

TABLE 4: Comparative analysis of the results of two kinds of jets formed by two kinds of tandem shaped charge penetrating targets.

\begin{tabular}{lccccc}
\hline & \multicolumn{2}{c}{ Penetrating reactive armor } & \multicolumn{3}{c}{ Penetrating main armor } \\
Type & Double-copper & Double-material & Double-copper & Double-material & Enhancement \\
\hline Numerical & Detonated & Undetonated & $627 \mathrm{~mm}$ & $721 \mathrm{~mm}$ & $15.0 \%$ \\
Experimental & Detonated & Undetonated & $615 \mathrm{~mm}$ & $703 \mathrm{~mm}$ & $14.3 \%$ \\
Comparative & Consistent & Consistent & Basically consistent & Basically consistent & Basically consistent \\
\hline
\end{tabular}

\section{Conclusions}

(1) Based on the research purpose of the damage performance of tandem shaped charge penetrating armor target wearing reactive armor, the structure model and finite element model of tandem shaped charge penetrating "reactive armor" were established. Based on the penetration depth of the armored target, the finite element software was used to study the numerical simulation of tandem shaped charge penetrating armored target under explosion loading. The influence of copper charge liner and modified PTFE charge liner on the penetration performance of tandem shaped charge was analyzed.

(2) The numerical simulation results show that the $\mathrm{Cu}$ jet formed by the tandem shaped charge of doublecopper material had strong impact performance, and the interlayer explosive in the reactive armor was detonated during the penetration of the reactive armor, which weakened the ability of the rear-stage main jet penetrating armor. The penetration depth of the main armor was only $627 \mathrm{~mm}$. However, in the process of penetrating the reactive armor, the double-material tandem shaped charge did not detonate the Sandwich explosive in the reactive armor, and the front-stage modified PTFE jet and the rear-stage main jet were not affected by the explosion loading before penetrating the main armor. The penetration depth of the main armor was $721 \mathrm{~mm}$, which was $15.0 \%$ higher than the penetration ability of the double-copper tandem shaped charge.

(3) Through the experiments of the tandem shaped charge penetrating into the armor wearing reactive armor, it was proved that after the front-stage charge adopted the modified PTFE charge liner, under the action of explosion loading, the front-stage jet penetrated but not detonated reactive armor. It solved the engineering problem that the front-stage jet penetrated and detonated reactive armor, which affected the penetration power of the rear-stage main 
jet to the main armor. The experimental results show that the double-material tandem shaped charge overcame the shortcoming of the influence of the front-stage explosion, and the penetration depth of the main armor reached $703 \mathrm{~mm}$, which was $14.3 \%$ higher than the penetration ability of the doublecopper tandem shaped charge, which was basically consistent with the numerical simulation results. It provides a reference for improving the damage ability of tandem shaped charge to armored target.

\section{Data Availability}

The data that support the findings of this study are available from the corresponding author upon reasonable request.

\section{Conflicts of Interest}

The authors declare that they have no conflicts of interest.

\section{Acknowledgments}

This work is financially supported by the National Natural Science Foundation of China (grant no. 11572291) and the Fund Project of Science and Technology on Transient Impact Laboratory (grant no. 6142606191105).

\section{References}

[1] K. Zhong, Research on Broken Hole-Embedded Tandem Warhead, Dissertation of the Nanjing University of Science and Technology, Nanjing, China, 2011.

[2] W. Cai, Study on Warhead Separation Technology, Dissertation of the Nanjing University of Science and Technology, Nanjing, China, 2008.

[3] D. Wang, "Analysis of the development of foreign anti-tank missiles," Flying Missiles, vol. 5, pp. 52-57, 2010.

[4] X. An and W. Fang, "A typical anti-tank missile in the United States," Foreign Tanks, vol. 10, pp. 35-36, 2012.

[5] J. Y. Yi, Z. J. Wang, J. P. Yin, and B. H. Chang, "Numerical simulation of steel target penetration by shaped charge distended jet with a high-polymer liner," Strength of Materials, vol. 49, no. 1, pp. 27-36, 2017.

[6] J. Y. Yi, Z. J. Wang, and J. P. Yin, "Simulation study on expansive jet formation characteristics of polymer liner," Materials, vol. 12, pp. 473-470, 2019.

[7] J. Yi and Z. Wang, "Damage characteristics of polymer expansive jet based on the crater growth enhanced effect," Materials Express, vol. 9, no. 7, pp. 732-740, 2019.

[8] B. V. Rumyantsev, "Penetration kinetics of a cumulative jet into brittle materials," Technical Physics, vol. 54, no. 6, pp. 790-794, 2009.

[9] S. V. Fedorov and Y. M. Bayanova, "Penetration of long strikers under hydrodynamic conditions with allowance for the material compressibility," Technical Physics, vol. 56, no. 9, pp. 1266-1271, 2011.

[10] X. Bai, J. X. Liu, and S. K. Li, "Effect of interaction mechanism between jet and target on penetration performance of shaped charge liner," Materials Science and Engineering A-Structural Material, vol. 553, pp. 142-148, 2012.

[11] X. Jia, Z.-X. Huang, X.-D. Zu, X.-H. Gu, C.-S. Zhu, and Z.-W. Zhang, "Experimental study on the performance of woven fabric rubber composite armor subjected to shaped charge jet impact," International Journal of Impact Engineering, vol. 57, pp. 134-144, 2013.

[12] X. Jia, Z.-X. Huang, X.-D. Zu, X.-H. Gu, and Q.-Q. Xiao, "Theoretical analysis of the disturbance of shaped charge jet penetrating a woven fabric rubber composite armor," International Journal of Impact Engineering, vol. 65, pp. 69-78, 2014.

[13] M. Held, "Effectiveness of an ERA-sandwich with a large distance between sandwich and target," Propellants, Explosives, Pyrotechnics, vol. 26, no. 1, pp. 33-37, 2001.

[14] M. Held, "Momentum theory of explosive reactive armours," Propellants, Explosives, Pyrotechnics, vol. 26, pp. 59-67, 2001.

[15] M. Held, "Stopping power of explosive reactive armours against different shaped charge diameters or at different angles," Propellants, Explosives, Pyrotechnics, vol. 26, no. 2, pp. 97-104, 2001.

[16] M. Held, "Time-distance plots for era-design," Propellants, Explosives, Pyrotechnics, vol. 26, no. 5, pp. 258-260, 2001.

[17] M. Held, "Jet initiation of covered high explosives with different materials," Propellants, Explosives, Pyrotechnics, vol. 27, no. 2, pp. 88-93, 2002.

[18] M. Held, "Dynamic plate thickness of era sandwiches against shaped charge jets," Propellants, Explosives, Pyrotechnics, vol. 29, no. 4, pp. 244-246, 2004.

[19] M. Held, "Time distance diagram of the jet initation of covered high explosive charges," International Journal of Impact Engineering, vol. 34, no. 4, pp. 702-707, 2007.

[20] F. Zeng, X. Ma, and X. Liang, "Initiation mechanism and the measurment of criterion value for jets on double reactive armor," Journal of Beijing Institute of Technology, vol. 16, pp. 621-625, 1996.

[21] S. Yao and S. Mi, "Numerical simulation and experimental research on the initiation of explosive reactive armor impacted by jet at large stand-off," Journal of Ordnance Engineering College, vol. 28, pp. 16-20, 2016.

[22] M. Held, "Initiation criteria of high explosives attacked with projectiles of different densities," in Proceedings of the 27th International Annual Conference of ICT, Karlsruhe, Germany, June 1996.

[23] H. Cao, Study on the Penetration-But-Not-Detonated of the ERA, Dissertation of the Nanjing University of Science and Technology, Nanjing, China, 2006.

[24] J. P. Yin, B. B. Gao, Z. J. Wang, and C. L. Zhao, "A comparative study of damage performance of the kill element from different materials," Strength of Materials, vol. 49, no. 1, pp. 20-26, 2017.

[25] B. H. Chang, J. P. Yin, and Z. Q. Cui, "Numerical simulation of modified low-density jet penetrating shell charge," International Journal of Simulation Modelling, vol. 14, no. 3, pp. 426-437, 2015.

[26] S. Xu and S. Yang, "Research advance in mechanical performance of filled PTFE Composite," Chemical Propellants and Polymeric Materials, vol. 6, pp. 8-12, 2008.

[27] W. Ying, Study on Mechanical Properties of PTFE Composites Reinforced by Filling Modification, Dissertation of the Jiangsu University, Zhenjiang, China, 2006.

[28] P. König and F. Mostert, "The design and performance of non-initiating shaped charges with granular jets against ERA," in Proceedings of the 20th International Symposium on Ballistics, pp. 858-863, Orlando, FL, USA, September 2002.

[29] J. Chen, J. Yin, and Y. Han, "Numerical simulation of low density particle jets formation based on SPH method," Chinese Journal of Energetic Materials, vol. 25, pp. 756-762, 2017. 